\title{
Clinical Study \\ Clinical Performance of Viscous Glass Ionomer Cement in Posterior Cavities over Two Years
}

\author{
Roland Frankenberger, ${ }^{1}$ Franklin Garcia-Godoy, ${ }^{2,3}$ and Norbert Krämer ${ }^{4}$ \\ ${ }^{1}$ Department of Operative Dentistry and Endodontics, Medical Center for Dentistry, University Medical Center Giessen and Marburg, \\ Georg-Voigt-Street 3, 35039 Marburg, Germany \\ ${ }^{2}$ College of Dentistry, University of Tennessee, 875 Union Avenue, Memphis, TN 38163, USA \\ ${ }^{3}$ The Forsyth Institute, 140 Fenway, Boston, MA 02115, USA \\ ${ }^{4}$ Department of Pediatric Dentistry, Medical Center for Dentistry, University Medical Center Giessen and Marburg, \\ Schlangenzahl 14, 35392 Giessen, Germany
}

Correspondence should be addressed to Roland Frankenberger, frankbg@med.uni-marburg.de

Received 22 July 2009; Accepted 7 December 2009

Recommended by Toru Nikaido

In this controlled prospective clinical study the highly viscous glass ionomer cement Ketac Molar was clinically assessed in Class I and Class II cavities. Forty-nine subjects (mean age 32.3 years) received 108 restorations placed by six operators in conventional Black I and II type cavities with undercuts after excavating primary lesions or after removing insufficient restorations. At baseline, and after 6, 12, and 24 months, restorations were assessed by two independent investigators according to modified USPHS codes and criteria. Impressions of the restorations were taken and epoxy replicas were made. Between the baseline and the 24-month recall, 51 representative samples were analyzed at $130 \times$ magnification by use of a stereo light microscope (SLM). Recall rates were $83 \%$ after 6 months, $50 \%$ after 12 months, and $24 \%$ after 24 months. Failure rates after 24 months were $8 \%$ for Class I and $40 \%$ for Class II fillings, mainly due to bulk fracture at occlusally loaded areas (Kaplan Meier survival analysis). Significant changes over time were found for the criteria "surface roughness", "marginal integrity", "restoration integrity", and "overall judgement" $(P<.05$; Friedman test). SLM analysis revealed statistically significant differences for the following criteria over time (baseline/6 months/12 months (in \% of entire evaluable margin length); $P<.05$; Friedman 2-way ANOVA): perfect margin 37/19/11, negative step formation 26/49/57, gap formation $2 / 7 / 9$, and overhang 24/11/8. Replicas exhibited mainly negative step formation as main finding due to apparently inferior wear resistance $(P<.05)$. Gap formations were more frequently observed in Class II restorations than in Class I ( $12 \%$ versus 3\% after 12 months; $P<.05$, Mann-Whitney- $U$ test). The evaluated margin lengths were not statistically different $(P>.05$, Friedman 2-way ANOVA).

Copyright ( 2009 Roland Frankenberger et al. This is an open access article distributed under the Creative Commons Attribution License, which permits unrestricted use, distribution, and reproduction in any medium, provided the original work is properly cited.

\section{Introduction}

Since the introduction of glass ionomer cements (GICs) by Wilson and Kent, many modifications of these materials have been performed over the years [1]. Classical GIC powder consists of silica, alumina, calcium fluoride as flux, cryolite, sodium fluoride, and/or aluminum phosphate. These raw materials are heated up to $1100-1500^{\circ} \mathrm{C}$, resulting in fluoroaluminiumsilicate glass, which is milled to powder. The fluid phase is compolymerized acrylic and itaconic acid or maleic or tricarboxylic acid [2]. Water balance is fundamentally important for an optimum setting reaction, any difference during or shortly after the setting reaction severely decreases physical properties [3]. This particular problem was solved by introducing capsule materials [4-6].

In order to improve mechanical properties, manufacturers added silver (e.g., Ketac Silver, 3M Espe, Seefeld, Germany) or increased viscosity by reducing filler size (e.g., Ketac Molar, 3M Espe; Ionofil Molar, Voco, Cuxhaven, Germany; Fuji IX, GC, Tokyo, Japan) in order to achieve a certain packability [7-9].

GICs were characterized as fluoride releasing [10, 11], which also recently was found to be protective against biofilm challenge as restorative $[12,13]$ and as luting cement 
for metallic restorations [14]. On the other hand, clinical outcome was not automatically favorable when GIC was used as restorative material [15-17]. At least initially, the introduction of GIC was connected with hopes of being able to replace amalgam. Especially in Europe, this was an interesting aspect because amalgam was more and more disregarded during the 1990's [15-17] with many amalgam restorations having been replaced by GIC.

In primary molars, several studies showed that GIC is not recommendable for Class II cavities due to unacceptable high fracture rates; however, Class I cavities may be restored [18-24]. In the permanent dentition, prospective studies have been rarely published. However, retrospective trials repeatedly reported unsatisfactory clinical performance in Class II cavities [25]. Reviews indicated that the annual failure rate with GIC is estimated to be around $8 \%[15,21]$.

Therefore, the aim of the present clinical trial was to prospectively calculate the potential of a highly viscous GIC for restoring posterior cavities in permanent molars. The null hypothesis was that there would be no difference between Classes I and II cavities regarding clinical outcome.

\section{Materials and Methods}

All patients were required to give written informed consent. The study was conducted according to EN 540 (Clinical investigation of medical devices for human subjects, European Committee for Standardization), and inspected by a local ethics committee. Al patients participated voluntarily. Patients selected for this study met the following criteria: (1) absence of pain from the tooth to be restored; (2) absence of any active periodontal and pulpal desease.

Fifty-five subjects ( 31 female, 24 male, mean age 33.0 years) received 108 GIC restorations. Twenty one restorations were placed in Class I and ninety four in Class II cavities. All restorations were made by four experienced dentists in a University dental clinic ( 31 bicuspids, 84 molars, 51 upper teeth, 64 lower teeth). Reasons for replacement were caries $(n=47)$, deficient restoration, that is, fracture or gap formation with exposed dentin $(n=68)$.

All restorations were inserted in permanent vital teeth without pain symptoms. For macromechanical retention, all cavities were made with undercuts. The cavities were cut using $1 \mathrm{~mm}$ wide coarse diamond burs under profuse water cooling ( $80 \mu \mathrm{m}$ diamond, Komet, Lemgo, Germany), and finished with a $25 \mu \mathrm{m}$ finishing diamond (Komet). Inner angles of the cavities were rounded and the margins were not bevelled. Prior to restorative treatment, the depth and width of the cavities was measured with a periodontal probe.

According to the manufacturer's recommendations, cavities were pretreated with Ketac Conditioner. Cavities were isolated with cotton rolls. Deep portions of the cavities (estimated remaining dentin thickness of $<200 \mu \mathrm{m}$ ) were covered with calcium hydroxide (Calxyl, OCO, Dirnstein, Germany). Ketac Molar Maxicap was mixed for 12 seconds in a RotoMix (3M Espe) apparatus. The GIC was applied into the cavity in one layer and adapted to the cavity walls with a plugger. The restorations were protected with Ketac Glaze (3M Espe) and light-cured for 20 seconds.

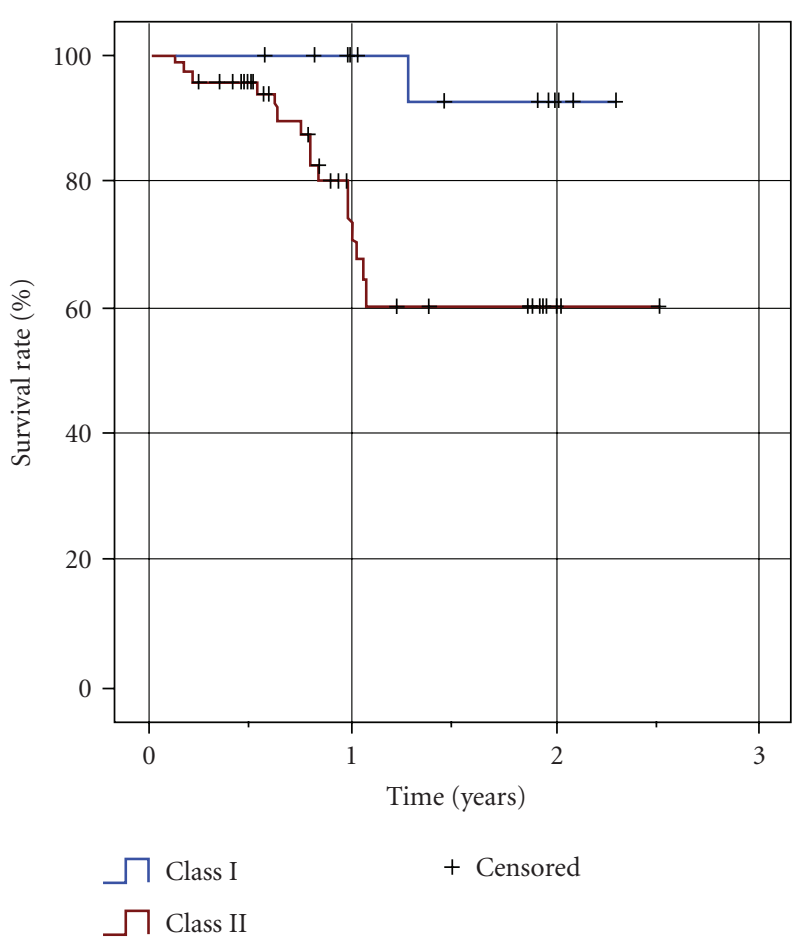

Figure 1: Kaplan-Meier survival curve.

After application of the glaze, rotary adjustment was performed at least 5 minutes later. Visible overhangs were removed with a scaler. Contacts in centric and eccentric occlusion were controlled with foils (Roeko, Langenau, Germany) and adjusted with finishing diamonds (Komet). Finally the restoration was shaped with silicon instruments (GC polishing set, GC Europe, Leuven, Belgium).

At the initial recall (baseline), and after 6, 12, and 24 months, available restorations were assessed according to modified United States Public Health Service (USPHS) criteria by two independent investigators using mirrors, probes, bitewing radiographs, impressions (Dimension Penta and Garant, 3M Espe), and intraoral photographs. Recall assessments were not performed by the clinician who placed the restorations. Impressions were used to make epoxy replicas (Epoxy Die, Ivoclar Vivadent, Principality of Liechtenstein). 51 replicas were selected for stereo light microscopic (SLM) analysis, SLM replicas were assessed at 130-fold magnification under a stereo light microscope (SV 11, Zeiss, Jena, Germany) in combination with a 3 CCD color camera (Sony, Cologne, Germany) and a frame grabber (Matrox Meteor RGB, AVT Horn, Aalen, Germany). The KS 100 software (Jenoptik, Jena, Germany) was used for digitization and WinMes 2.0 software was used for margin analysis. Marginal integrity was expressed as percentage of the entire evaluable margin length. Marginal quality was classified according to the criteria "perfect margin", "gap/irregularity", "negative step", "positive step", "overhang", and "not judgeable/artifact" [26]. 
TABle 1: Descriptive statistics for all Ketac Molar restorations.

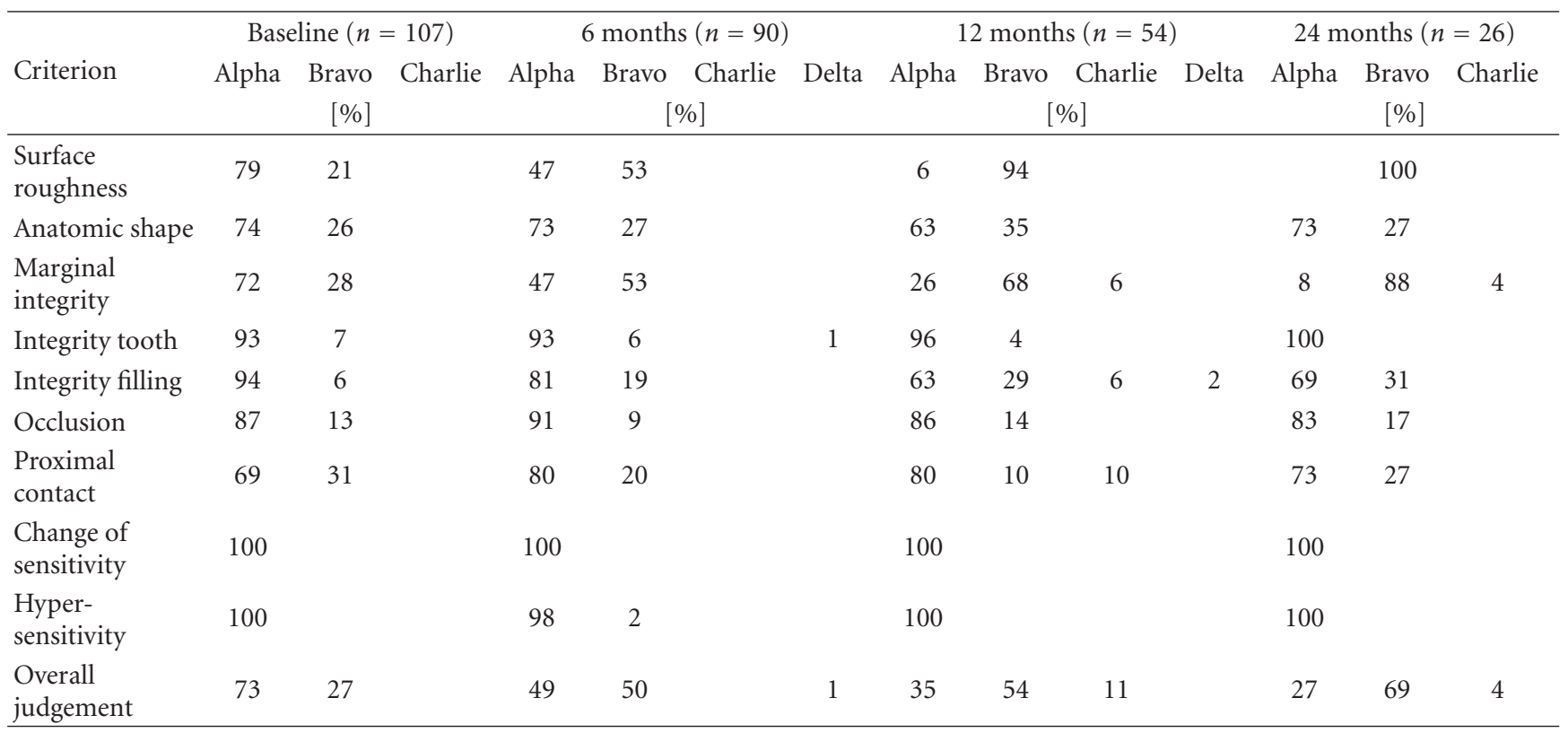

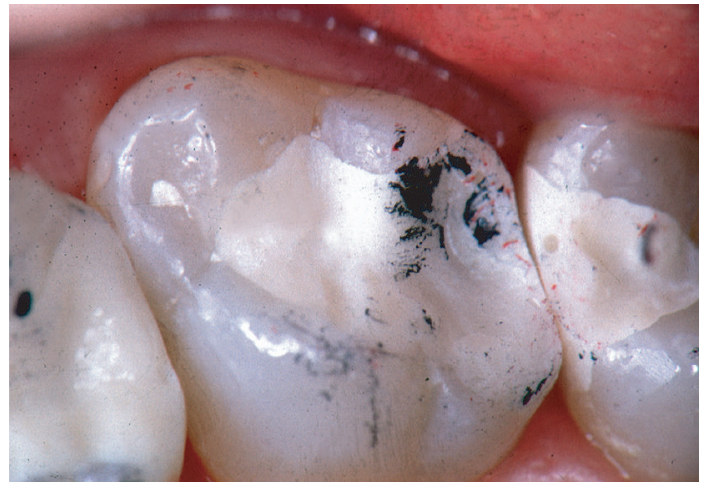

FIgUre 2: Ketac Molar restoration at baseline. The occlusal contact area was marked with Occlu-foil.

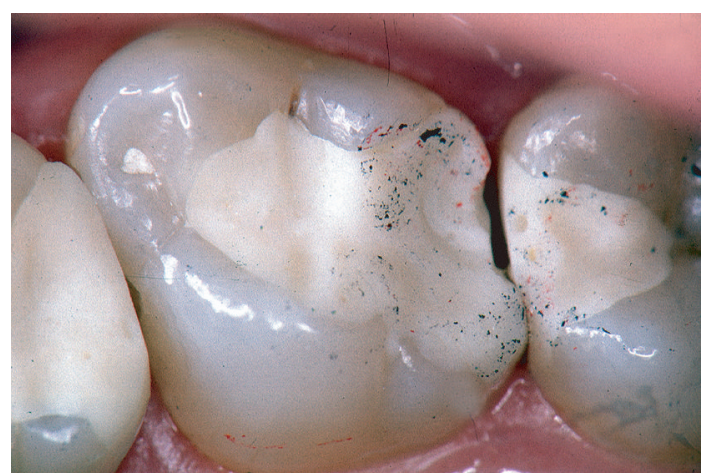

Figure 3: Ketac Molar restoration after 6 months. Chipping occured in the occlusal-proximal contact area.

Statistical appraisal was computed with SPSS for Windows XP 15.0 (SPSS Inc., Chicago, IL, USA). Statistical unit

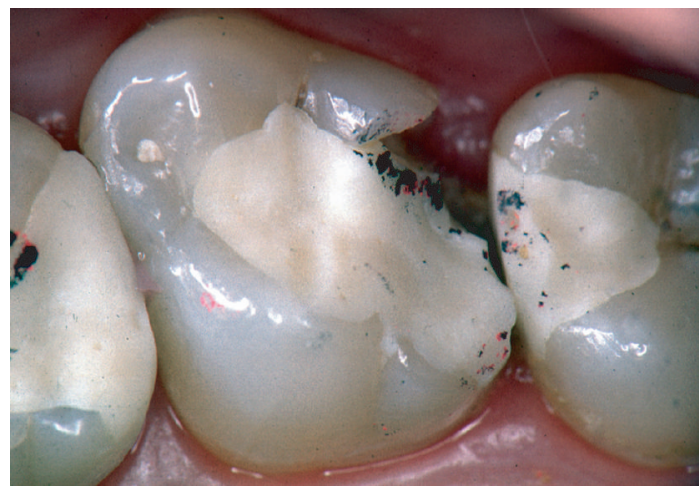

FIGURE 4: Ketac Molar restoration after 12 months. Half of the proximal box was lost.

was one tooth, differences between groups were evaluated using the Mann-Whitney $U$-test, changes over time were calculated with the Friedman test $(P=.05)$.

\section{Results}

Details about clinical outcome of the GIC restorations are displayed in Table 1 . After 12 months, 54 restorations were evaluated, and after 24 months of clinical service, 26 restorations were available for recall assessments. The reasons for not qualifying for recall visits were missed recall $(n=52)$, prosthetic measures like crown preparations $(n=$ 10 ), and other non-material-specific reasons like extraction $(n=2)$. This means a drop-out rate of $76 \%$ over the 24 month period. Failure rates after 24 months were $8 \%$ for Class I and $40 \%$ for Class II restorations (Kaplan-Meier survival curve; Figure 1). Seventeen Class II restorations had to be replaced due to material-specific reasons (bulk fracture 


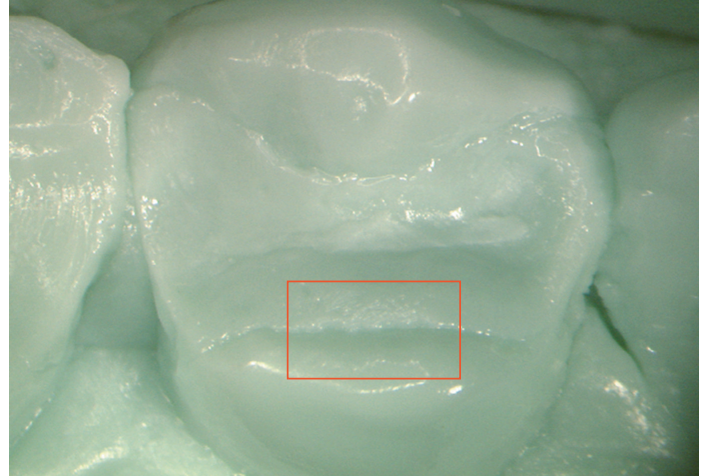

Figure 5: Epoxy replica of a Ketac Molar filling after 12 months. A distinct crevice is evident.

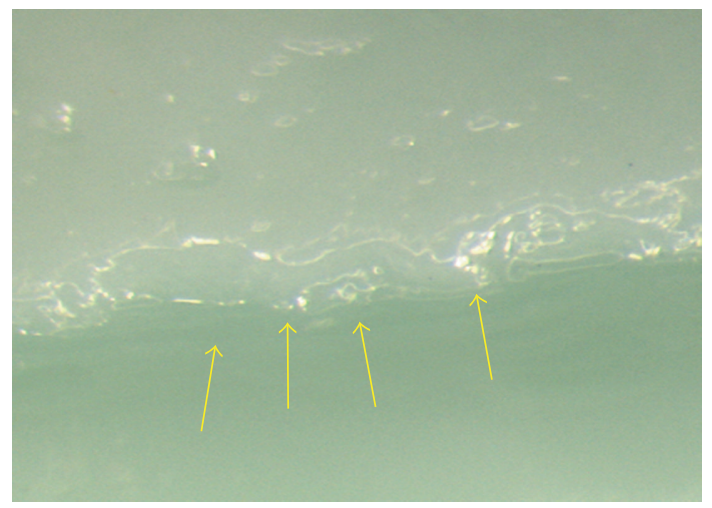

Figure 6: Magnification of the palatal aspect of Figure 5. No gap was detectable.

$n=9$; hypersensitivity $n=4$; gap formation $n=3$; tooth fracture $n=1$; complete loss of the restoration $n=1$; Figures $1,3$, and 4$)$.

Significant changes over time were found for the criteria "surface roughness", "marginal integrity", "restoration integrity", and "overall judgement" (Friedman test; $P<$ .05; Table 1). After 6 months, one "delta" resulted from a tooth fracture, and after 12 months, three "Charlie" ratings resulted from marginal fractures with lost proximal contact (Figures 2-4). One restoration suffered complete retention loss ("delta"; Table 1).

An overview of SLM observations is shown in Table 2. The results of the SLM marginal analysis revealed significant differences concerning the criteria "perfect margin", changes in "positive step formation", "negative step formation" (Figures 5 and 6), "overhang", "marginal fracture", and "gap formation" over time (Friedman test, $P<.05$; Table 2). Between cavity size and failure no correlation could be computed (Mann-Whitney $U$-test, $P>.05$; Table 3 ).

\section{Discussion}

The merits of GICs as restorative materials for both dentitions are clearly reflected by the literature in the field: GICs show fluoride release $[7,10,11,18]$ and consequently offer
TABLE 2: SLM margin analysis of all restorations.

\begin{tabular}{lccc}
\hline & $\begin{array}{c}\text { Baseline } \\
(n=51)\end{array}$ & $\begin{array}{c}6 \text { months } \\
(n=48)\end{array}$ & $\begin{array}{c}12 \text { months } \\
(n=39)\end{array}$ \\
Length $[\mu \mathrm{m}]$ & $\begin{array}{c}15.6 \times 10^{3} \\
\left(5.5 \times 10^{3}\right)\end{array}$ & $\begin{array}{c}15.3 \times 10^{3} \\
\left(5.4 \times 10^{3}\right)\end{array}$ & $\begin{array}{c}17.2 \times 10^{3} \\
\left(5.3 \times 10^{3}\right)\end{array}$ \\
\hline Criterion & & & \\
Perfect margin & $36.0 \%$ & $18.5 \%$ & $10.9 \%$ \\
Negative step & $(21.7)$ & $(17.8)$ & $(14.7)$ \\
Formation & $25.6 \%$ & $49.3 \%$ & $57.1 \%$ \\
Gap formation & $(22.9)$ & $(23.9)$ & $(21.3)$ \\
& $2.1 \%$ & $7.1 \%$ & $9.8 \%$ \\
Overhang & $(4.7)$ & $(10.1)$ & $(12.4)$ \\
Positive step & $23.5 \%$ & $11.3 \%$ & $8.7 \%$ \\
Formation & $(20.1)$ & $(13.1)$ & $(9.8)$ \\
Marginal & $6.1 \%$ & $3.1 \%$ & $1.7 \%$ \\
Fracture & $(9.3)$ & $(8.1)$ & $(5.8)$ \\
Artifact & $0.0 \%$ & $1.2 \%$ & $1.7 \%$ \\
& $(0.0)$ & $(3.8)$ & $(5.0)$ \\
\hline
\end{tabular}

some potential to inhibit secondary caries $[7,10,14,27-30]$. GICs were even discussed as pit and fissure sealing material with some protective aspects even after retention loss $[8,31$, 32]. Furthermore, GIC is the ideal material for atraumatic restorative techniques $[29,33-36]$ and seems to reveal some advantages concerning long-term costs in routine dental restorative treatment because handling is quick and easy $[9,37,38]$.

Although a variety of clinical trials with different kinds of GIC as permanent restorative materials was carried out in primary molars $[18-24,39,40]$, not a single prospective clinical medium or long term trial is published about GIC in permanent molars. Retrospective studies primarily reported dissapointing outcomes when GIC was applied in average cavities $[15,21,25]$ and slightly better results when minimum intervention cavities were restored with conventional GIC $[41,42]$. This observation was not confirmed by the present study, because here no influence of cavity size on clinical outcome was found. Much more important was the occlusal contact situation (Figures 2-4) with a clear correlation of contact points on lateral ridges and bulk fractures exactly in these areas of special risk. And this is only true for Class II restorations with a higher load situation compared to Class I restorations where the brittle GIC material is always completely surrounded by enamel and dentin.

A retrospective study of Mjor doubted the previous assumption that GIC as permanent restorative material is really able to counteract secondary caries formation after a certain time of clinical service [43,44]. The time span of the present investigation may be too short to contribute to this rather important question, however, several other shortcomings of GIC materials are clearly reflected here such as flexural fatigue behaviour. 
TABLE 3: Cavity size related to survival of restorations after one year.

\begin{tabular}{|c|c|c|c|c|c|}
\hline \multirow{2}{*}{ Measured margin length } & \multicolumn{2}{|c|}{ Intact restorations } & \multicolumn{2}{|c|}{ Fractured restorations } & \multirow{2}{*}{$\begin{array}{c}\text { Level of significance } \\
\text { (Mann-Whitney } U \text {-Test) }\end{array}$} \\
\hline & $\mathrm{N}$ & mean $[\mathrm{mm}]$ & $n$ & mean $[\mathrm{mm}]$ & \\
\hline \multicolumn{6}{|l|}{ (1) Width at the isthmus } \\
\hline (a) mesially & 19 & 4.16 & 6 & 4.18 & 1.00 \\
\hline (b) distally & 10 & 4.18 & 5 & 3.62 & 0.13 \\
\hline \multicolumn{6}{|l|}{ (2) Maximum width of proximal box } \\
\hline (a) mesially & 19 & 5.25 & 6 & 5.43 & 0.73 \\
\hline (b) distally & 10 & 5.66 & 5 & 5.22 & 0.59 \\
\hline \multicolumn{6}{|l|}{ (3) Vestibular height at isthmus } \\
\hline (a) mesially & 14 & 2.83 & 6 & 3.73 & 0.13 \\
\hline (b) distally & 8 & 3.39 & 4 & 4.30 & 0.11 \\
\hline \multicolumn{6}{|l|}{ (4) Height at isthmus } \\
\hline (a) mesially & 14 & 2.84 & 6 & 3.74 & 0.44 \\
\hline (b) distally & 8 & 3.43 & 4 & 4.75 & 0.21 \\
\hline (5) Maximum cavity width Transversally & 35 & 5.61 & 9 & 5.13 & 0.53 \\
\hline (6) Maximum cavity width mesio-distally & 3 & 7.58 & 9 & 7.04 & 0.80 \\
\hline
\end{tabular}

When routine clinical long-term trials dealing with restorative materials or even more expensive indirect restorations are carried out accordingly, drop-out rates are normally within a low range. This enables the researcher to draw profound conclusions about clinical performance when a certain time of clinical service is over $[15,16]$. From our experience it is obvious that the major disadvantage of prospective clinical trials dealing with cheapest and aesthetically compromised restorations such as GIC in permanent molars is drop out of patients. Of course, high drop-out numbers are potentially corroborating clinical conclusions and recommendations. This was the case in the present clinical investigation. All patients participated voluntarily, so they did not lose money or so when not showing up again. Nevertheless, there are some results with substantial impact on the overall judgement of the clinically investigated material.

Already after 12 months of clinical service, $34 \%$ of Class II GIC restorations had failed, meaning a 34\% annual failure rate, which is five times higher than retrospective assumptions of cross-sectional studies exhibited [15, 21, 25]. Facing the circumstances of the reported rather high drop out in this study, we can conclude that at least one third of restorations had already failed after 12 months. We take the right to speculate that from the overall population of patients considerably more restorations failed during this 24 months period but were not available for recall. Even when defensively calculating the poor 24 months result, we still face a $20 \%$ annual failure rate which is still more than two times higher than reported in evaluations and reviews of a solely retrospective nature. Finally it has to be considered that the high drop out numbers definitely could bias the results.

Also marginal analyses under a SLM clearly show the inferior potential of GIC in Class II cavities being attributable to extensive wear and insufficient flexural strength as well as fatigue behaviour [45].

Altogether, the discussion about GICs is subclassified into two major aspects. On one hand, GICs offer fluoride release and easy handling properties, making them almost ideal for treatment of uncooperative children, covering of root caries, and performing ART projects. On the other hand, the moisture-sensitive setting reaction and the still way inferior flexural strength and flexural fatigue behaviour do not allow a recommendation of GICs for durable restorations of Class II cavities in permanent molars. Class I restorations exhibited a significantly better clinical outcome over the observation period of 24 months. Therefore, the null hypothesis had to be rejected because there was a distinct difference between Class I and Class II cavities.

\section{Conclusions}

Highly viscous GIC showed unacceptable high failure rates in Class II cavities, irrespective of cavity size. Annual failure rates of $20 \%$ are substantially higher than estimated from retrospective clinical trials. However, the high drop out observed in this study limits its significance.

\section{References}

[1] A. D. Wilson and B. E. Kent, "A new translucent cement for dentistry. The glass ionomer cement," British Dental Journal, vol. 132, no. 4, pp. 133-135, 1972.

[2] J. O. Burgess, B. K. Norling, and J. B. Summit, "Resin ionomer restorative materials-the new generation," in Glass Ionomers: The Next Generation. Proceedings of the 2nd International Symposium on Glass Ionomers, P. R. Hunt, Ed., pp. 75-86, Colophon, Philadelphia, Pa, USA, 1994.

[3] G. J. Mount, "Lessons from the past," in Glass Ionomers: The Next Generation. Proceedings of the 2nd International Symposium on Glass Ionomers, P. R. Hunt, Ed., pp. 89-100, Colophon, Philadelphia, Pa, USA, 1994.

[4] R. Peez and S. Frank, "The physical-mechanical performance of the new Ketac Molar Easymix compared to commercially available glass ionomer restoratives," Journal of Dentistry, vol. 34, no. 8, pp. 582-587, 2006. 
[5] G. J. P. Fleming and D. M. Zala, "An assessment of encapsulated versus hand-mixed glass ionomer restoratives," Operative Dentistry, vol. 28, no. 2, pp. 168-177, 2003.

[6] A. D. Wilder Jr., A. A. Boghosian, S. C. Bayne, H. O. Heymann, J. R. Sturdevant, and T. M. Roberson, "Effect of powder/liquid ratio on the clinical and laboratory performance of resinmodified glass-ionomers," Journal of Dentistry, vol. 26, no. 4, pp. 369-377, 1998.

[7] W. D. Browning, "The benefits of glass ionomer self-adhesive materials in restorative dentistry," Compendium of Continuing Education in Dentistry, vol. 27, no. 5, pp. 308-314, 2006.

[8] M. J. Tyas, "Milestones in adhesion: glass-ionomer cements," Journal of Adhesive Dentistry, vol. 5, no. 4, pp. 259-266, 2003.

[9] J. W. Nicholson and T. P. Croll, "Glass-ionomer cements in restorative dentistry," Quintessence International, vol. 28, no. 11, pp. 705-714, 1997.

[10] A. T. Hara, C. P. Turssi, M. Ando, et al., "Influence of fluoridereleasing restorative material on root dentine secondary caries in situ," Caries Research, vol. 40, no. 5, pp. 435-439, 2006.

[11] A. Wiegand, W. Buchalla, and T. Attin, "Review on fluoridereleasing restorative materials-fluoride release and uptake characteristics, antibacterial activity and influence on caries formation," Dental Materials, vol. 23, no. 3, pp. 343-362, 2007.

[12] H. K. Yip, J. Guo, and W. H. S. Wong, "Protection offered by root-surface restorative materials against biofilm challenge," Journal of Dental Research, vol. 86, no. 5, pp. 431-435, 2007.

[13] A. T. Hara, C. P. Turssi, M. Ando, et al., "Influence of fluoridereleasing restorative material on root dentine secondary caries in situ," Caries Research, vol. 40, no. 5, pp. 435-439, 2006.

[14] J. S. Moura, E. M. Lima, A. F. Paes Leme, A. A. Del Bel Cury, C. P. M. Tabchoury, and J. A. Cury, "Effect of luting cement on dental biofilm composition and secondary caries around metallic restorations in situ," Operative Dentistry, vol. 29, no. 5, pp. 509-514, 2004.

[15] J. Manhart, H. Y. Chen, G. Hamm, and R. Hickel, "Buonocore Memorial Lecture. Review of the clinical survival of direct and indirect restorations in posterior teeth of the permanent dentition," Operative Dentistry, vol. 29, no. 5, pp. 481-508, 2004.

[16] R. Hickel and J. Manhart, "Longevity of restorations in posterior teeth and reasons for failure," Journal of Adhesive Dentistry, vol. 3, no. 1, pp. 45-64, 2001.

[17] G. J. Mount, "Buonocore Memorial Lecture. Glass-ionomer cements: past, present and future," Operative Dentistry, vol. 19, no. 3, pp. 82-90, 1994.

[18] N. Krämer, U. Lohbauer, and R. Frankenberger, "Restorative materials in the primary dentition of poli-caries patients," European Archives of Paediatric Dentistry, vol. 8, no. 1, pp. 2935, 2007.

[19] B. L. Chadwick and D. J. Evans, "Restoration of Class II cavities in primary molar teeth with conventional and resin modified glass ionomer cements: a systematic review of the literature," European Archives of Paediatric Dentistry, vol. 8, no. 1, pp. 1421, 2007.

[20] Y. Yilmaz, O. Eyuboglu, M. E. Kocogullari, and N. Belduz, "A one-year clinical evaluation of a high-viscosity glass ionomer cement in primary molars," Journal of Contemporary Dental Practice, vol. 7, no. 1, pp. 71-78, 2006.

[21] R. Hickel, C. Kaaden, E. Paschos, V. Buerkle, F. Garcia-Godoy, and J. Manhart, "Longevity of occlusally-stressed restorations in posterior primary teeth," American Journal of Dentistry, vol. 18, no. 3, pp. 198-211, 2005.
[22] R. J. Smales, H. C. Ngo, K. H.-K. Yip, and C. Yu, "Clinical effects of glass ionomer restorations on residual carious dentin in primary molars," American Journal of Dentistry, vol. 18, no. 3, pp. 188-193, 2005.

[23] N. Krämer and R. Frankenberger, "Clinical performance of a condensable metal-reinforced glass ionomer cement in primary molars," British Dental Journal, vol. 190, no. 6, pp. 317-321, 2001.

[24] R. Frankenberger, J. Sindel, and N. Krämer, "Viscous glassionomer cements: a new alternative to amalgam in the primary dentition?" Quintessence International, vol. 28, no. 10, pp. 667676, 1997.

[25] J. D. Scholtanus and M.-C. Huysmans, "Clinical failure of class-II restorations of a highly viscous glass-ionomer material over a 6-year period: a retrospective study," Journal of Dentistry, vol. 35, no. 2, pp. 156-162, 2007.

[26] A. R. Braun, R. Frankenberger, and N. Krämer, "Clinical performance and margin analysis of ariston $\mathrm{pHc}$ versus Solitaire I as posterior restorations after 1 year," Clinical Oral Investigations, vol. 5, no. 3, pp. 139-147, 2001.

[27] R. J. Mhaville, W. E. van Amerongen, and G. J. Mandari, "Residual caries and marginal integrity in relation to Class II glass ionomer restorations in primary molars," European Archives of Paediatric Dentistry, vol. 7, no. 2, pp. 81-84, 2006.

[28] H. C. Ngo, G. Mount, J. Mc Intyre, J. Tuisuva, and R. J. Von Doussa, "Chemical exchange between glass-ionomer restorations and residual carious dentine in permanent molars: an in vivo study," Journal of Dentistry, vol. 34, no. 8, pp. 608-613, 2006.

[29] M. Bonecker, C. Toi, and P. Cleaton-Jones, "Mutans streptococci and lactobacilli in carious dentine before and after Atraumatic Restorative Treatment," Journal of Dentistry, vol. 31, no. 6, pp. 423-428, 2003.

[30] M. J. Tyas, "Cariostatic effect of glass ionomer cement: a fiveyear clinical study," Australian Dental Journal, vol. 36, no. 3, pp. 236-239, 1991.

[31] S. A. Antonson, J. Wanuck, and D. E. Antonson, "Surface protection for newly erupting first molars," Compendium of Continuing Education in Dentistry, vol. 27, no. 1, pp. 46-52, 2006.

[32] G. J. Mount, "Clinical performance of glass-ionomers," Biomaterials, vol. 19, no. 6, pp. 573-579, 1998.

[33] N. K. Ersin, U. Candan, A. Aykut, O. Oncag, C. Eronat, and T. Kose, "A clinical evaluation of resin-based composite and glass ionomer cement restorations placed in primary teeth using the ART approach: results at 24 months," Journal of the American Dental Association, vol. 137, no. 11, pp. 1529-1536, 2006.

[34] J. P. D. L. Menezes, A. Rosenblatt, and E. Medeiros, "Clinical evaluation of atraumatic restorations in primary molars: a comparison between 2 glass ionomer cements," Journal of Dentistry for Children, vol. 73, no. 2, pp. 91-97, 2006.

[35] L. Wang, L. G. Lopes, E. Bresciani, J. R. Lauris, R. F. Mondelli, and M. F. Navarro, "Evaluation of Class I ART restorations in Brazilian schoolchildren: three-year results," Special Care in Dentistry, vol. 24, no. 1, pp. 28-33, 2004.

[36] C. Yu, X.-J. Gao, D.-M. Deng, H.-K. Yip, and R. J. Smales, "Survival of glass ionomer restorations placed in primary molars using atraumatic restorative treatment (ART) and conventional cavity preparations: 2-year results," International Dental Journal, vol. 54, no. 1, pp. 42-46, 2004.

[37] P. Sjögren, "Cost of composite and glass ionomer Class II molar restorations and theoretical analyses of cost per year of function at Public Dental Services in Sweden," Swedish Dental Journal, vol. 30, no. 3, pp. 99-107, 2006. 
[38] G. J. Mount, "Longevity in glass-ionomer restorations: review of a successful technique," Quintessence International, vol. 28, no. 10, pp. 643-650, 1997.

[39] V. Qvist, L. Laurberg, A. Poulsen, and P. T. Teglers, "Eight-year study on conventional glass ionomer and amalgam restorations in primary teeth," Acta Odontologica Scandinavica, vol. 62, no. 1, pp. 37-45, 2004.

[40] L. A. M. Marks, W. E. Van Amerongen, P. J. Borgmeijer, H. J. Groen, and L. C. Martens, "Ketac molar versus Dyract Class II restorations in primary molars: twelve month clinical results," Journal of Dentistry for Children, vol. 67, no. 1, pp. 37-41, 2000.

[41] R. L. Zanata, M. F. Navarro, S. H. Barbosa, J. R. Lauris, and E. B. Franco, "Clinical evaluation of three restorative materials applied in a minimal intervention caries treatment approach," Journal of Public Health Dentistry, vol. 63, no. 4, pp. 221-226, 2003.

[42] G. J. Mandari, J. E. Frencken, and M. A. van't Hof, "Six-year success rates of occlusal amalgam and glass-ionomer restorations placed using three minimal intervention approaches," Caries Research, vol. 37, no. 4, pp. 246-253, 2003.

[43] I. A. Mjör, "Glass-ionomer cement restorations and secondary caries: a preliminary report," Quintessence International, vol. 27, no. 3, pp. 171-174, 1996.

[44] I. A. Mjör and A. Jokstad, "Five-year study of Class II restorations in permanent teeth using amalgam, glass polyalkenoate (ionomer) cermet and resin-based composite materials," Journal of Dentistry, vol. 21, no. 6, pp. 338-343, 1993.

[45] U. Lohbauer, R. Frankenberger, A. Clare, A. Petschelt, and P. Greil, "Toughening of dental glass ionomer cements with reactive glass fibres," Biomaterials, vol. 25, no. 22, pp. 52175225,2004 


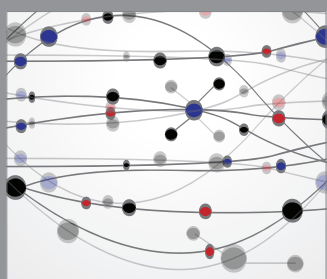

The Scientific World Journal
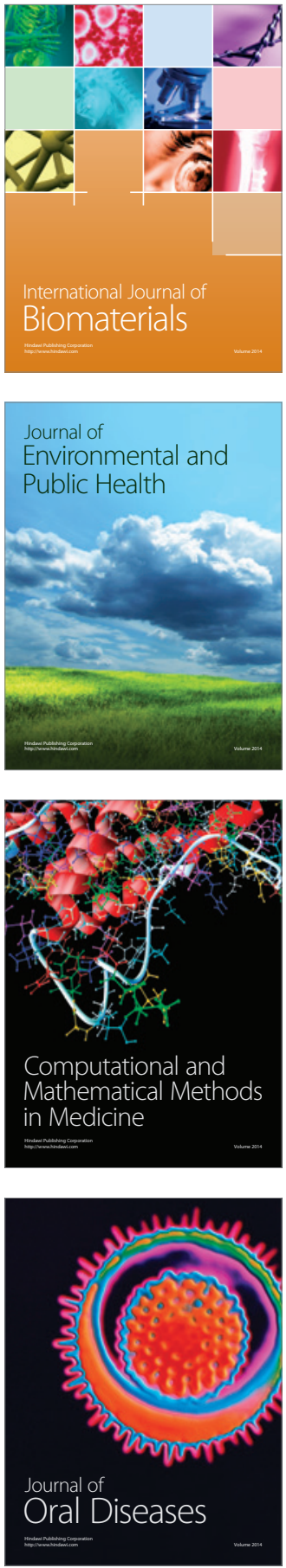
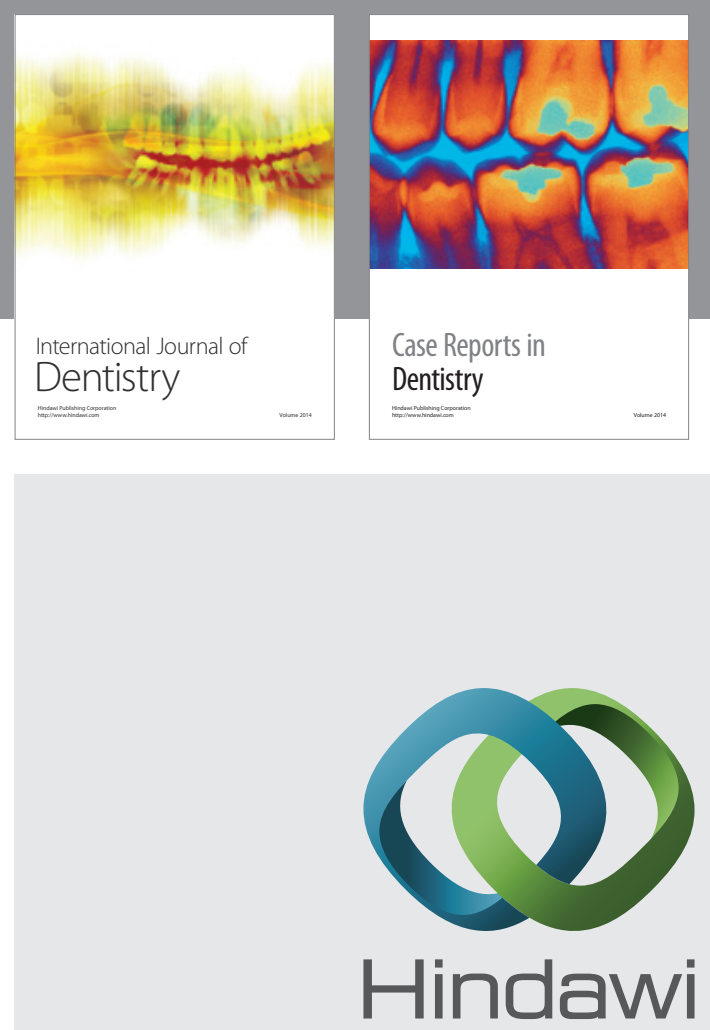

Submit your manuscripts at

http://www.hindawi.com
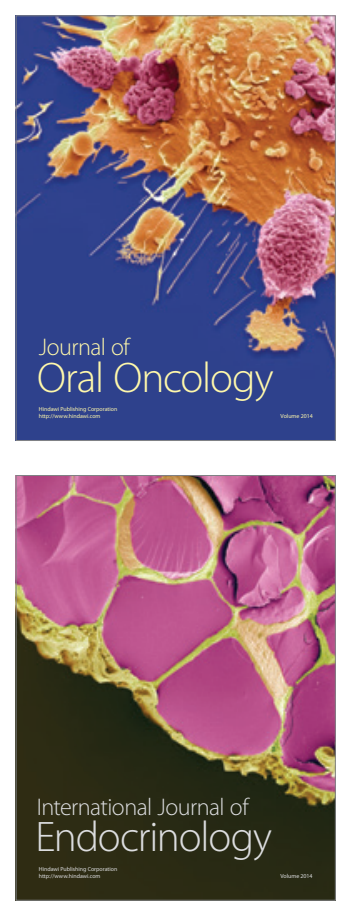
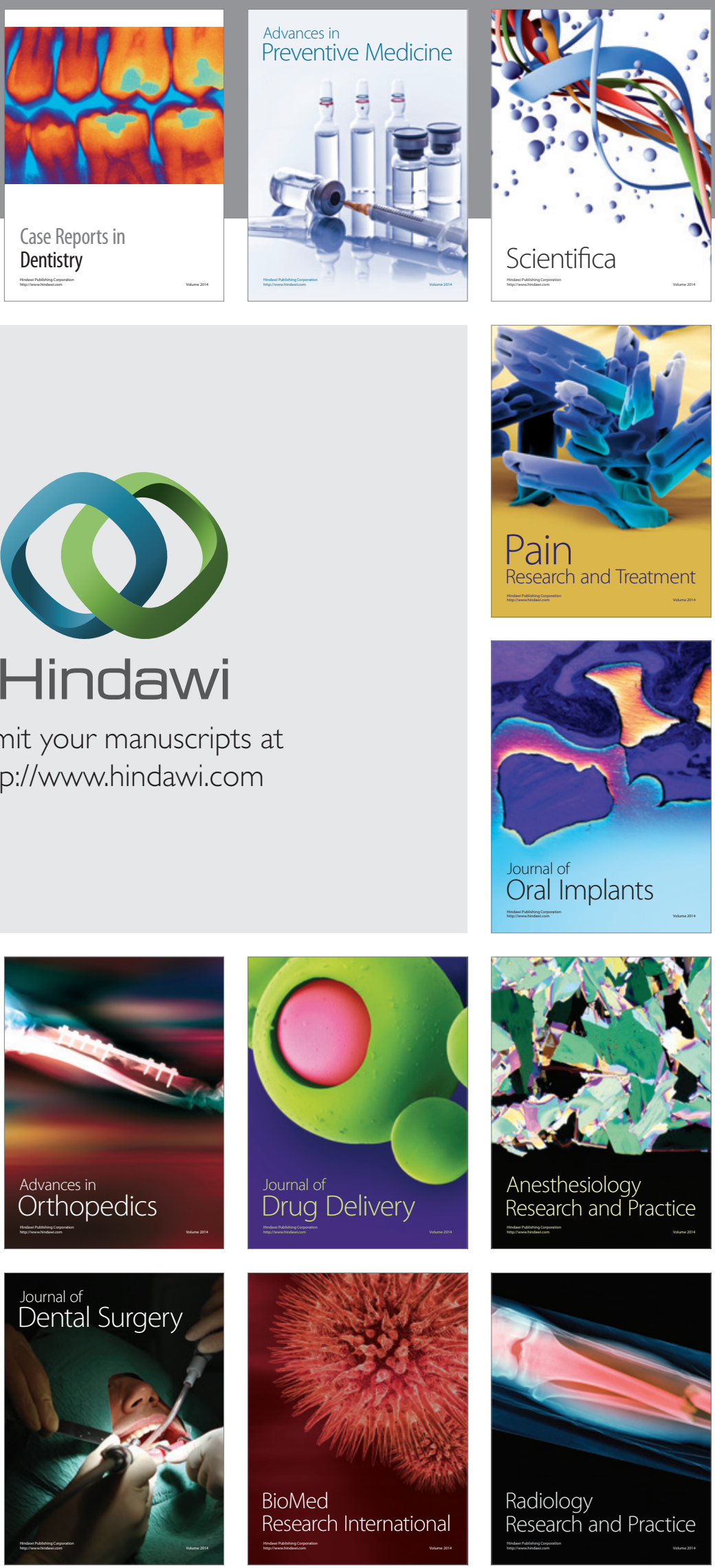